\title{
Cost Optimization Modeling of Renewable Energy Sources in Smart-Grid Using SCADA
}

\author{
Nafisa Islam*, Warsame H. Ali, Emmanuel S Kolawole, John Fuller, Pamela Obiomon, \\ John O. Attia, Samir Abood \\ Department of Electrical and Computer Engineering, Prairie View A \& M University, Prairie View, USA \\ Email: ^nislam1@student.pvamu.edu,whali@pvamu.edu, ekolawole@student.pvamu.edu, jhfuller@pvamu.edu, \\ joattia@pvamu.edu,pobiomon@pvamu.edu
}

How to cite this paper: Islam, N., Ali, W.H., Kolawole, E.S., Fuller, J., Obiomon, P., Attia, J.O. and Abood, S. (2021) Cost Optimization Modeling of Renewable Energy Sources in Smart-Grid Using SCADA. Communications and Network, 13, 51-67. https://doi.org/10.4236/cn.2021.132005

Received: October 17, 2020

Accepted: May 18, 2021

Published: May 21, 2021

Copyright $\odot 2021$ by author(s) and Scientific Research Publishing Inc. This work is licensed under the Creative Commons Attribution International License (CC BY 4.0).

http://creativecommons.org/licenses/by/4.0/

\begin{abstract}
In recent times, renewable energy production from renewable energy sources is an alternative way to fulfill the increased energy demands. However, the increasing energy demand rate places more pressure, leading to the termination of conventional energy resources. However, the cost of power generation from coal-fired plants is higher than the power generation's price from renewable energy sources. This experiment is focused on cost optimization during power generation through pumped storage power plant and wind power plant. The entire modeling of cost optimization has been conducted in two parts. The mathematical modeling was done using MATLAB simulation while the hydro and wind power plant's emulation was performed using SCADA (Supervisory control and data acquisition) designer implementation. The experiment was conducted using ranges of generated power from both power sources. The optimum combination of output power and cost from both generators is determined via MATLAB simulation within the assumed generated output power range. Secondly, the hydro-generator and wind generator's emulation were executed individually through synchronizing the grid to determine each generator's specification using SCADA designer, which provided the optimum power generation from both generators with the specific speed, aligning with results generated through MATLAB. Finally, the operational power cost (with no losses consideration) from MATLAB was compared with the local energy provider to determine the cost-efficiency. This experiment has provided the operational cost optimization of the hydro-wind combined power system with stable wind power generation using SCADA, which will ultimately assist in operations of large-scale power systems, remotely minimizing multi-area dynamic issues while maximizing the system efficiency.
\end{abstract}




\section{Keywords}

Smart-Grid, Cost Optimization, Economic Dispatch, SCADA, Renewable Energy Sources, MATLAB

\section{Introduction}

The increasing energy demand rate places more pressure on the termination of conventional energy resources. Therefore, it has become a significant phenomenon to balance this extensive energy demand by enforcing the proper use of resources that already existed and implementing new resources to optimize the cost accordingly. On the other hand, the depletion of fossil fuels like coal, petroleum, natural gas, etc. is creating an adverse effect on the environment. Global warming, emissions of greenhouse gases, climate change are the negative impact that is associated with nature is being produced by fossil fuel-based energy generation.

Energy management is the energy policy algorithm, planning, execution, and actions to propagate resource conservation, climate protection, and cost savings while sufficient energy demand is being fulfilled. The optimization of using new renewable energy sources connecting with the previous existing resources may cause distinct complications. Cost optimization is the process that attempts to function cost reduction disciplines with the standard pricing, simplifies the platform, and executes the plan/application related to cost for a particular item. Economic dispatch (ED) defines the system providing the demand load over the appointed units with the lowest power production cost [1]. The dispatch operating department can focus on the indicated aspects to influence the economic dispatch accomplishment procedures, which provides the accomplishment to function and optimize the power system with decent quality, economy, and environmental security protection [2] [3] [4] [5] [6]. Moreover, ED is considered the simplest to formulate on a long-term basis instead of utilizing the power system daily efficiently. To overcome this shortcoming, the investigation of the problem should be not just focused on economic viewpoint but also should direct the question into multiple time intervals with different and interconnected power systems [7]. Regarding these (Multi-Area Dynamic ED) MADED problems, literature [8] illustrated a spectacle for reducing the cost of consumption by assuming the percolation of wind power and pumped storage power plants. The pumped storage power station has also become the economic peaking power supply because of its flexibility, reliability, and capacity. A combination of wind and pumped storage power plants are considered financial and the solution to this problem. Pumped storage utilization helps to smooth and improve the fluctuations of the combined power generation system of wind and pumped storage power plants. Literature [9] portrays an optimization prototype for wind power plant, which contains the highest efficacy and steady output power with 
the proposed optimization model of the non-dominant sequencing genetic algorithm with elite strategy. Wind generator control, limitation of power and management for pumped storage, mismatch of selling cost and penalty cost between the assigned and the supplied energy leads to the cost reduction of the system [10]. A strategy that helps solve scheduling issues also plays an essential role in making the system economical [11]. The researchers emphasized various facts to improve the load fluctuation, power integration, and cost optimization due to the multiple constraints in applying pumped storage and wind power plant. In the literature [12], the traditional numerical calculation of wind-hydro power stations has approached after a wind load combination to match the equivalent load. Literature [13] illustrated the model to progress the capacity of wind power integration. Furthermore, the reduction of wind power fluctuation is achieved by implementing the improved Bat algorithm that portrayed the pumped storage-wind combined power system [14]. In the beginning, the focus was on the individual power plant itself. Later on, many research types have been done to optimize jointly multiple power plants like wind-hydro, wind-hydro-thermal, wind-solar-thermal, etc. Literature [9] [12] illustrated that a numerical algorithm to optimize the equivalent or the factuality of the wind power plant in the power system instead of focusing on cost optimization. Also, [13] [14] emphasized optimization by improving a numerical method, whereas it can be more focused on the operation and control.

In this literature, the hydro-wind power station's economic dispatch is calculated with a SCADA system considered modern technology. The phenomena of this technology are used to control the power flow from the generators to loads. The advantage of using the SCADA system is to maintain the microgrid's operating schedule by the smart grid communication technology as PLC. Also, the result obtained from the SCADA system is verified by MATLAB program code. But the benefit of using the SCADA system is to control the operating schedule remotely, while there is no such technique in MATLAB. Particularly, operation remotely by the SCADA system has been recommended more beneficial as MATLAB lacks this operation. Therefore, a concept has proposed to acquire the solution of these technical problems associated with the Smart Grid network worked as an integral part of the management scheme.

\section{Renewable Energy and Traditional System}

Renewable energy is the recollected energy from renewable resources. It can be defined that power and energy generated from different sources like solar, wind, ocean, hydropower, biomass, geothermal resources, and hydrogen originated from renewable resources.

\section{1) Pumped storage Power Plant}

The availability of water is an essential requirement for hydropower generation. Hydropower generates both kinetic energy and potential energy. Usually, the water from lakes and the water from reservoirs at an elevated level is the hy- 
dropower generation source. The hydroelectric power plant needs the generator coupled with the turbine with the rotation to generate power, HV/EHV transmission lines to connect with the other power plants altogether. A three-phase alternating current synchronous generator is used in pumped storage plants. The armature is housed in the stator consisting of a core and fame. The center acts as a magnetic circuit and is shaped by a massive steel ring built up of thin electrical quality sheet steel laminations. The excitation control adjusts the reactive load taken by each generator. Voltage regulators serve the purpose of maintaining the voltage of the turbine clenched on the desired value at the machine bus.

\section{2) Wind Power Plant}

\section{Typical Structure of Horizontal-Axis Wind Turbines:}

Figure 1(a) and Figure 1(b) displays the main modules of the HAWT rotor, which are blades and a central hub. The maintenance of designing the power train is less since the power train is situated over the HAWT tower. A passive yaw drive permits wind energy to adjust the nacelle. A rotor that contains two blades creates larger cyclical loads than a three-bladed rotor on the yaw drive.

\section{Typical Structure of Vertical-Axis Wind Turbines:}

Figure 2 shows the curved blades are secured with rigid upper and lower hubs and divided by the rotor column. Blades are shaped to a troposkien shape with zero bending stress to decrease internal bending stresses through the rotation, contains two or three fixed-pitch blades which are cross-sectionally equal.

\section{3) Induction Generator}

The induction generator converts mechanical energy into electrical energy like other generators. The power generated from wind energy involves the use of a Doubly-Fed Induction Generator (DFIG). A DFIGURE is used to dampen this disruption. A basic configuration of DFIGURE is shown below:

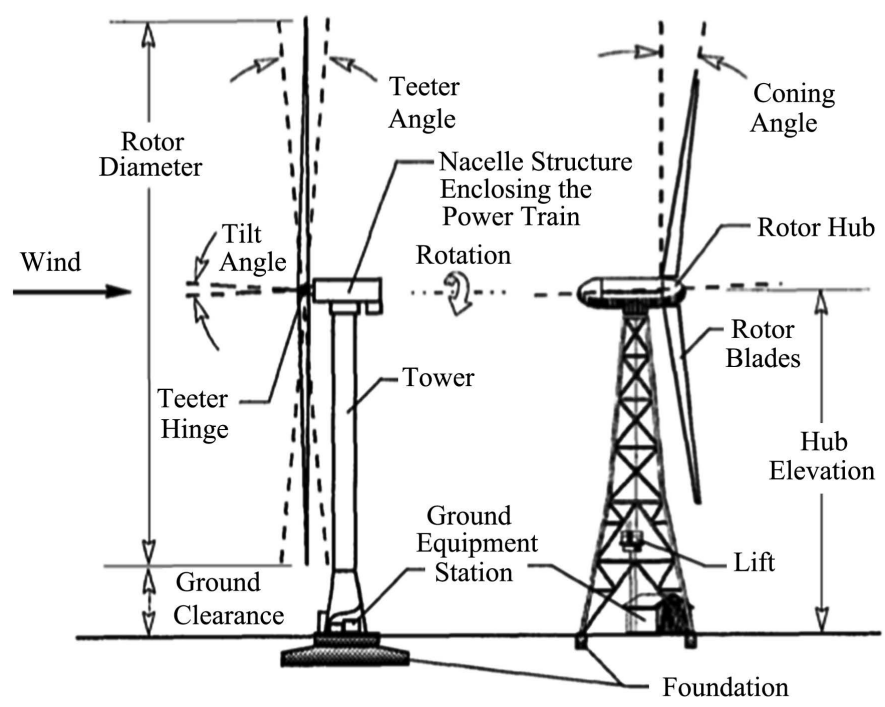

(a)

(b)

Figure 1. (a) Two-bladed teetered-hub upwind rotor; (b) Two-bladed rigid-hub downwind rotor. 


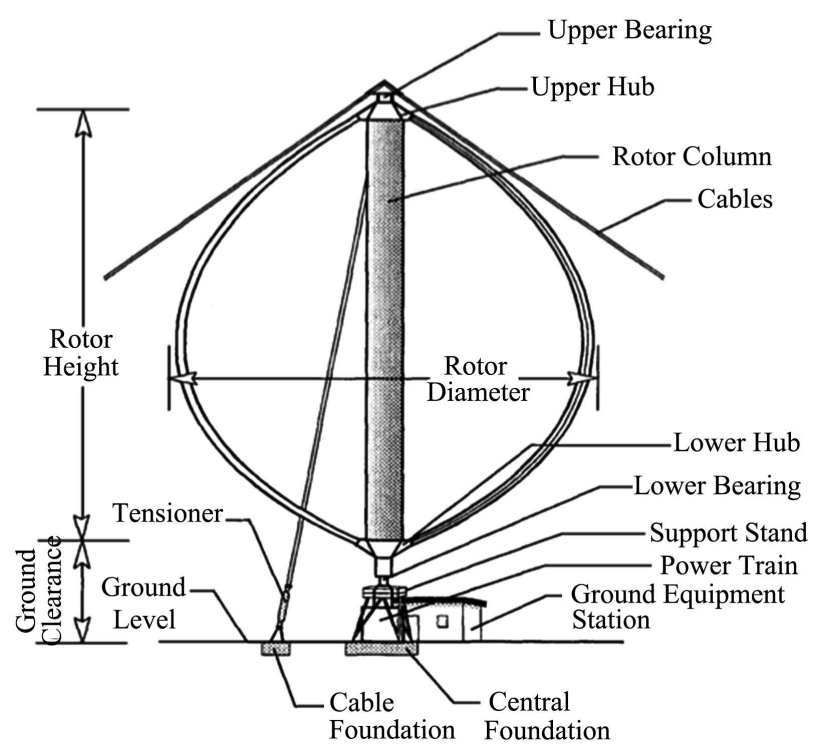

Figure 2. Schematic views of the principal components of a modern VAWT.

The generator consists of two converters: MSC and LSC shown in Figure 3. Also, the DC chopper and crowbar play an essential role when faults disrupt the system. When there is a constant wind energy input, the DFIGURE supplies the machine-side converter and generator with reactive power. During a period of disruption in unsteady wind energy, a voltage dip is noted and supplied reactive power can be stabilized through the line-side converter. When the system disrupts with the turbine's faulty power flow, it results in a high generation of energy between the machine-side converter and the line-side. This excess energy flowing from the rotor circuit into the MSC can be harnessed via a DC Chopper. Figure 4 shows the connection of the DC Chopper and crowbar to the DFIGURE that will be connected to the wind turbine.

\section{Transmission Line}

The transmission line is a medium to transmit to radiofrequency, voltages. A transmission line is a circuit along with distributed parameters, such as series resistance, series inductance, shunt capacitance, and shunt conductance are distributed along the whole length of the line, as shown in Figure 5.

The d.c resistance of several types of conductors at a specified temperature $T$ is found by:

$$
R_{d c . T}=\frac{\rho_{T} l}{A}
$$

where $\rho_{T}$ conductor resistivity at temperature $T(\Omega \cdot \mathrm{m})$

$L$-conductor length (m);

$A$-conductor cross-sectional area $\left(\mathrm{m}^{2}\right)$.

It is defined as the flux linkages per unit current,

$$
L=\frac{\psi}{I}
$$




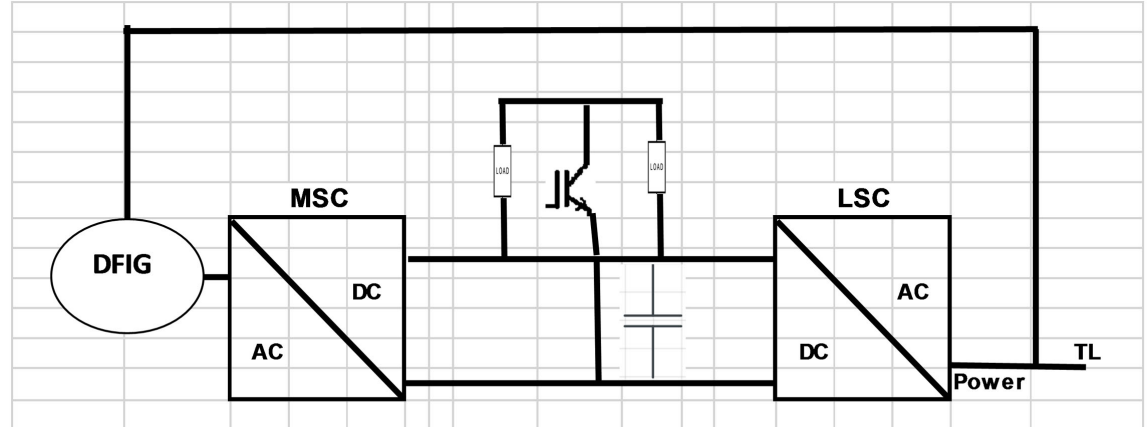

Figure 3. Operation characteristics of DFIG.

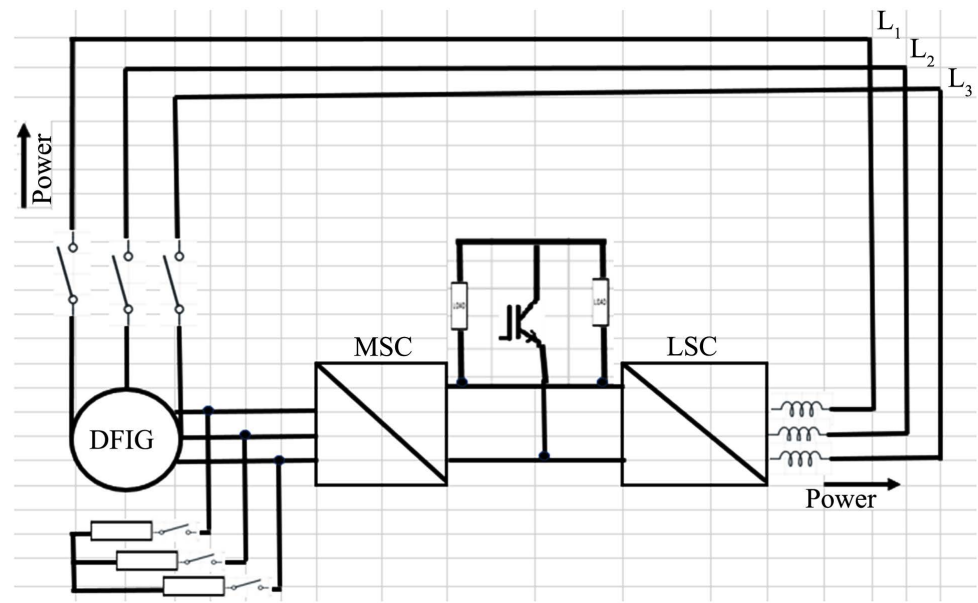

Figure 4. Crowbar in wind turbine.

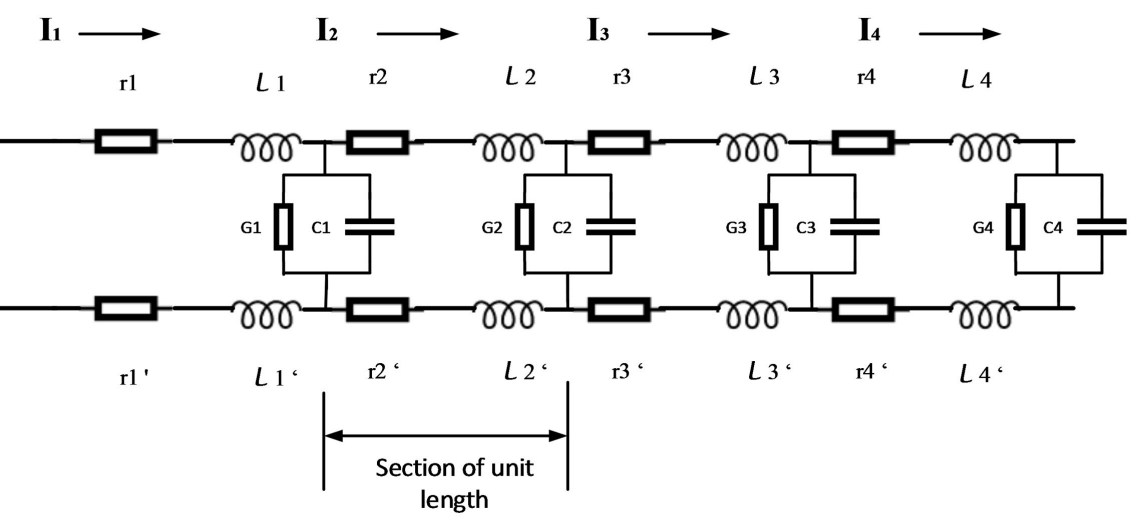

Figure 5. Parameters of overhead transmission lines.

where $\psi$ is flux linkage (Weber-turns)

$I$ is current (amperes);

$L$ is a constant of proportionality, inductance (henrys).

Potential difference is the number of charges through two points of a conductor.

$$
C=\frac{q}{V} \mathrm{~F} / \mathrm{m}
$$


Usually, the two conductors' capacitance is constant when placed in parallel, but this constant is subjected according to the conductors' size and placement.

The ratio of output power and input power of the transmission line is the transmission efficiency.

Transmission efficiency

$$
\eta_{T L}=\frac{\left(V_{r} I_{r}\right)(\cos \theta)}{\left(V_{S} I_{S}\right)\left(\cos \phi_{S}\right)} \times 100
$$

\section{Emulation of Renewable Energy Sources in the Smart Grid}

The cost optimization model has been executed into several steps in this section.

Step 1: The output power and cost calculation by MATLAB using an incremental cost function.

Step 2: This step has executed three case studies:

CASE 1: Dark lamp Manual synchronization to the grid for a pumped storage power plant to determine the pumped storage power plant's specification.

CASE 2: Grid synchronization for a DFIGURE to determine the wind power plant's specification.

CASE 3: Connection of hydro generator and wind generator to the grid to verify the MATLAB' stated result.

Step 3: Comparison of the mathematical results to the practical results.

\section{1) Step One:}

In this experiment, the range is assumed for pumped storage generator output power from $P_{1 \min }=10 \mathrm{~W}$ to $P_{1 \max }=200 \mathrm{~W}$. The range is considered for wind generator output power from $P_{2 \min }=10 \mathrm{~W}$ to $P_{2 \max }=150 \mathrm{~W}$. Therefore, the minimum and maximum generated load power range for the combination of pumped storage power plant and wind power plant system is $P_{L \min }=20 \mathrm{~W}$ to $P_{I \max }=350$ W.

The general cost $C$ is considered as,

$$
C=a P^{2}+b P+c ; \$ / h
$$

(with the consideration of no generator losses and limits) where $a, b$, and $c$ also represent cost but in constant cost, which will not be considered to optimize in this study, and $P$ is the generated power from the generator. The general cost is a function of output power of each power plant. The incremental cost of the two-power unit is a calculation of the slope of generating power and receiving the units' power curves. This cost helps to determine the optimum combination of power productions that reduces the total energy. Then, incremental cost $\lambda$ is,

$$
\lambda=\frac{\mathrm{d} C}{\mathrm{~d} P}=2 a P+b ; \$ / \mathrm{W} \cdot \mathrm{h}
$$

The general cost and incremental cost for a pumped-storage power plant is,

$$
\begin{gathered}
C_{1}=a_{1} P_{1}^{2}+b_{1} P_{1}+c_{1} ; \$ / \mathrm{h} \\
\lambda_{1}=\frac{\mathrm{d} C_{1}}{\mathrm{~d} P_{1}}=2 a_{1} P_{1}+b_{1} ; \$ / \mathrm{W} \cdot \mathrm{h}
\end{gathered}
$$


where $a_{1}, b_{1}$, and $c_{1}$ are considered as cost coefficients, $P_{1}$ is the output power from the pumped storage power plant.

The general cost and incremental cost for a wind power plant is,

$$
\begin{gathered}
C_{2}=a_{2} P_{2}^{2}+b_{2} P_{2}+c_{2} ; \$ / \mathrm{h} \\
\lambda_{2}=\frac{\mathrm{d} C_{2}}{\mathrm{~d} P_{2}}=2 a_{2} P_{2}+b_{2} ; \$ / \mathrm{W} \cdot \mathrm{h}
\end{gathered}
$$

where $a_{2}, b_{2}$, and $c_{2}$ are considered as cost coefficients, $P_{2}$ is the generated power from the wind power plant.

$$
\text { At optimum condition, } \lambda_{1}=\lambda_{2}=\lambda
$$

Equation (4.3) for the pumped storage power plant can be re-written as,

$$
C_{1}=0.0041 P_{1}^{2}+0.8 P_{1}+40 \$
$$

where, $a_{1}=0.0041, b_{1}=0.8$, the values are taken from [15]. As the machine under this experiment was in $\mathrm{W}$, the power specification was scaled with $\mathrm{W}$ according to the test stand.

From Equation (4.4), the incremental cost,

$$
\lambda_{1}=0.0082 P_{1}+0.8 \$ / \mathrm{W} \cdot \mathrm{h}
$$

Equation (4.5) for the wind power plant can be re-written as,

$$
C_{2}=0.0065 P_{2}^{2}+1.4 P_{2}+19 \$
$$

where 0.0065 and 1.4 are represented as constant $a_{2}$ and $b_{2}$ respectively, the values are also taken from [15] As the machine under this experiment was in W, the power specification was scaled with $\mathrm{W}$ according to the test stand.

From Equation (4.6), incremental cost,

$$
\lambda_{2}=0.013 P_{2}+1.4 \$ / \mathrm{W} \cdot \mathrm{h}
$$

As the minimum power for both of the power plant is $10 \mathrm{~W}$, and substitute $P_{1}$ $=10 \mathrm{~W}$ in Equation (4.8) which gives $\lambda_{1}=0.0082 \$ / \mathrm{W} \cdot \mathrm{h}$ and substitute $P_{2}=$ $10 \mathrm{~W}$ in Equation (4.10) which provides $\lambda_{2}=1.53 \$ / \mathrm{W} \cdot \mathrm{h}$.

It is observed that $\lambda_{1}<\lambda_{2}$, which means that the incremental cost of pumped storage is less than the wind power plant's incremental cost at minimum power generation of $10 \mathrm{~W}$ from both power plants. As the incremental cost of the wind power plant is higher than the pumped storage power plant during generating minimum power $10 \mathrm{~W}$, keeping the output power of wind power plant $P_{2}=10$ W constant for the next step and calculate $P_{1}=89 \mathrm{~W}$ when the system is in an optimum state, $\lambda_{1}=\lambda_{2}=1.53$ from Equation (4.8). The next steps will continue by assuming various values of the output power of the pumped storage power plant $P_{1}$, to calculate $P_{2}, P_{L}$, and incremental costs at optimum state $\lambda_{1}=\lambda_{2}=\lambda$. As mentioned before in this section, the maximum power is $200 \mathrm{~W}$ for pumped storage and $150 \mathrm{~W}$ for wind power plants. The same previous steps will continue to determine $P_{2}, P_{L}$, and incremental cost for assumed various $P_{1}$; until each power plants reach their appointed assumed maximum power, $200 \mathrm{~W}$ for $P_{1}$ and $150 \mathrm{~W}$ for $P_{2}$. Table 1 contains all the calculated values of $P_{2}, P_{L}, \lambda$ for various values of $P_{1}$ from the steps mentioned in Table 1 . 
Table 1. Power and incremental cost at optimum condition.

\begin{tabular}{cccc}
\hline $\begin{array}{c}P_{1} \\
\begin{array}{c}\text { Output power } \\
\text { from the pumped } \\
\text { storage power plant) }\end{array}\end{array}$ & $\begin{array}{c}P_{2} \\
\text { (Output power } \\
\text { from the wind } \\
\text { power plant) }\end{array}$ & $\begin{array}{c}P_{L} \\
\text { (Output power } \\
\text { from the } \\
\text { combined system) }\end{array}$ & $\begin{array}{c}\lambda \\
\text { (Incremental cost) }\end{array}$ \\
\hline $10 \mathrm{~W}$ & $10 \mathrm{~W}$ & $20 \mathrm{~W}$ & $\lambda_{1}=0.882 \$ / \mathrm{Wh}$ \\
$89 \mathrm{~W}$ & $10 \mathrm{~W}$ & $99 \mathrm{~W}$ & $\lambda_{1}=\lambda_{2}=1.53 \$ / \mathrm{Wh}$ \\
$120 \mathrm{~W}$ & $29.53 \mathrm{~W}$ & $149.53 \mathrm{~W}$ & $\lambda_{1}=\lambda_{2}=1.784 \$ / \mathrm{Wh}$ \\
$140 \mathrm{~W}$ & $42.153 \mathrm{~W}$ & $182.153 \mathrm{~W}$ & $\lambda_{1}=\lambda_{2}=1.948 \$ / \mathrm{Wh}$ \\
$160 \mathrm{~W}$ & $54.77 \mathrm{~W}$ & $214.77 \mathrm{~W}$ & $\lambda_{1}=\lambda_{2}=2.112 \$ / \mathrm{Wh}$ \\
$180 \mathrm{~W}$ & $67.38 \mathrm{~W}$ & $247.38 \mathrm{~W}$ & $\lambda_{1}=\lambda_{2}=2.276 \$ / \mathrm{Wh}$ \\
$200 \mathrm{~W}$ & $80 \mathrm{~W}$ & $280 \mathrm{~W}$ & $\lambda_{1}=\lambda_{2}=2.44 \$ / \mathrm{Wh}$ \\
$200 \mathrm{~W}$ & $150 \mathrm{~W}$ & $350 \mathrm{~W}$ & $\lambda_{2}=3.35 \$ / \mathrm{Wh}$ \\
\hline
\end{tabular}

Using all the values from Table 1, the optimum generated power combination of pumped storage plant, wind power plant, and the cost are determined by MATLAB shown in Table 2, where units 1 and 2 are named as pumped storage power plants and wind power plant.

Table 2 indicates the optimum point of the generated power, $88 \mathrm{~W}$ with 40.07 \$ for the pumped storage power plant, and $33.994 \mathrm{~W} 19.048$ \$ for the wind power plant, and the total cost is 59.118 \$.

Figure 6 shows the characteristics of output power $\left(P_{1}\right)$ of pumped storage plant versus incremental cost $\lambda$. Considering the power range $10 \mathrm{~W}<P_{1}<200$ $\mathrm{W}$. The curve is linear from $10 \mathrm{~W}$ to $200 \mathrm{~W}$. After reaching $200 \mathrm{~W}$, the incremental cost $\lambda$ changes from 2.44 to $3.35 \$ / W h$. As a result, the generated power is constant at this point.

Figure 7 indicates the characteristics of output power $\left(P_{2}\right)$ generated from the wind power plant and the incremental cost $\lambda$ considering the power range $10 \mathrm{~W}$ $<P_{1}<150 \mathrm{~W}$. The incremental cost $\lambda$ is constant when $P_{2}=10 \mathrm{~W}$, whereas it starts to act as linearly from $10 \mathrm{~W}$ to $150 \mathrm{~W}$ with increasing incremental cost $\lambda$ from 0.882 to $1.53 \$ / \mathrm{Wh}$.

Figure 8 shows the characteristics of the combined system's load power $\left(P_{\mathrm{L}}\right)$ versus incremental cost $\lambda$. This curve has three linear parts; first, the curve is linear from 10 to $100 \mathrm{~W}$ with increasing incremental cost $\lambda$. The second curve is linear from $100 \mathrm{~W}$ to approximately $280 \mathrm{~W}$ with increasing incremental cost $\lambda$, and the third one is linear from around $280 \mathrm{~W}$ to $350 \mathrm{~W}$.

\section{2) Step Two:}

Three experiments were done in this step. They are given below:

CASE 1: Dark lamp Manual synchronization to the grid for pumped storage power plant

Figure 9 shows the connection of the pumped storage generator to the grid. The machine under test is operated in the "synchronization" mode in the servo machine test with $1800 \mathrm{rpm}$ and $60 \mathrm{~Hz}$ frequency. 


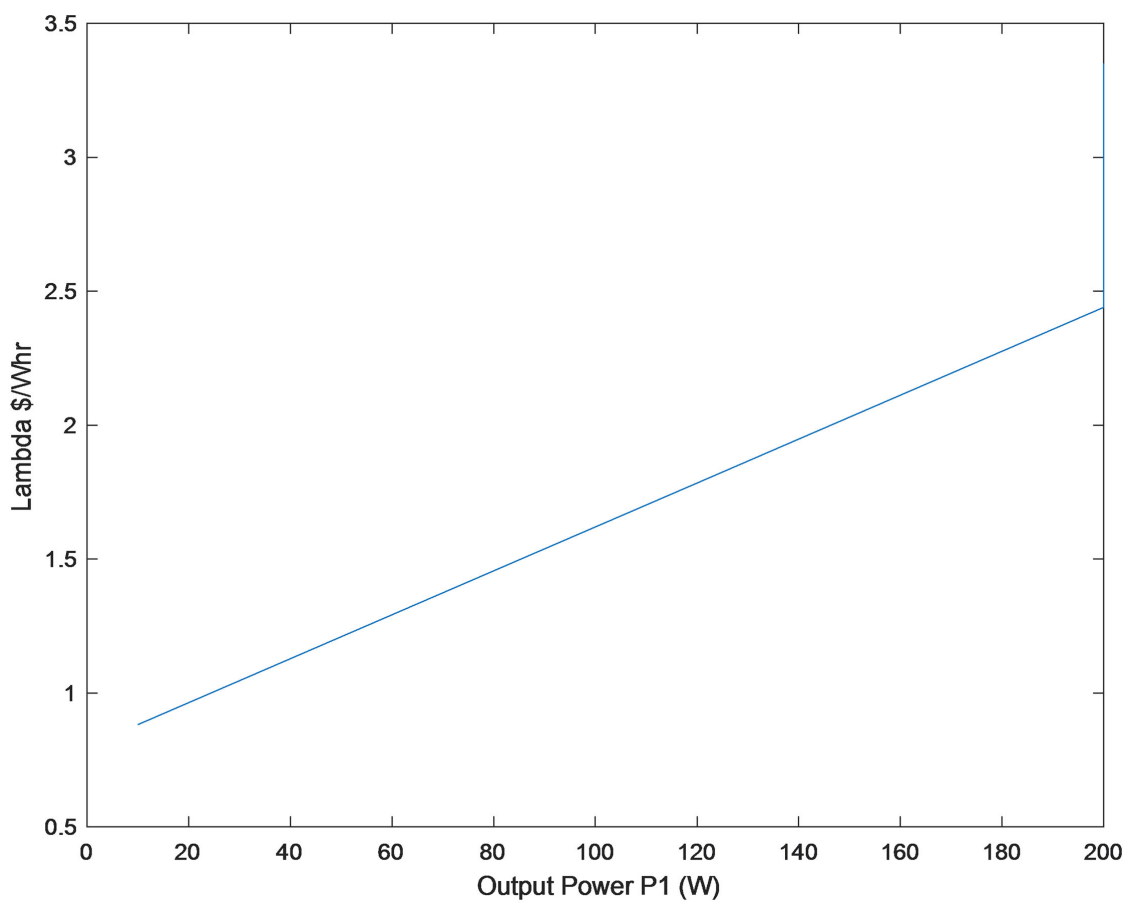

Figure 6. Power G1- $\lambda$ characteristics from MATLAB.

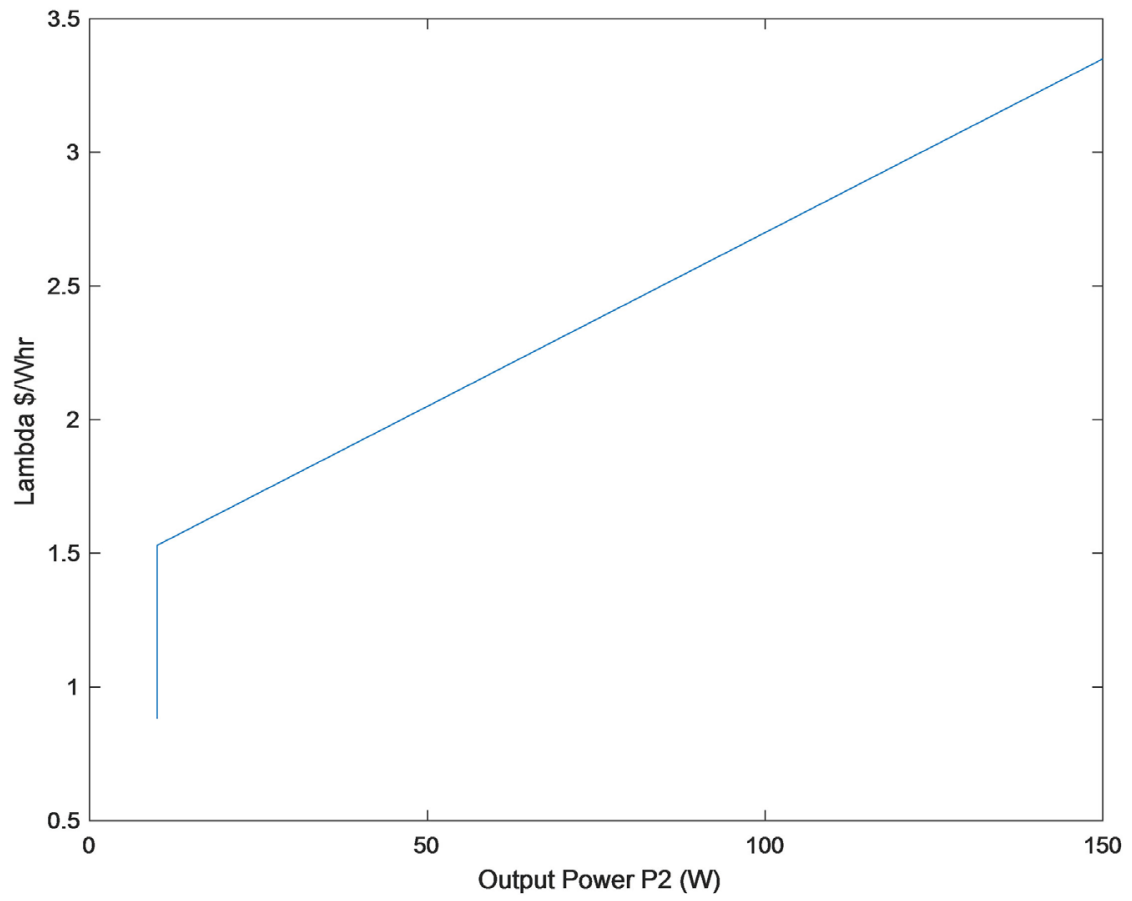

Figure 7. Power G2- $\lambda$ characteristics from MATLAB.

Table 2. The calculation from MATLAB.

\begin{tabular}{ccc}
\hline Unit & Output Power $(\mathrm{W})$ & Cost $(\$)$ \\
\hline 1 & 88 & 40.07 \\
2 & 33.994 & 19.048
\end{tabular}




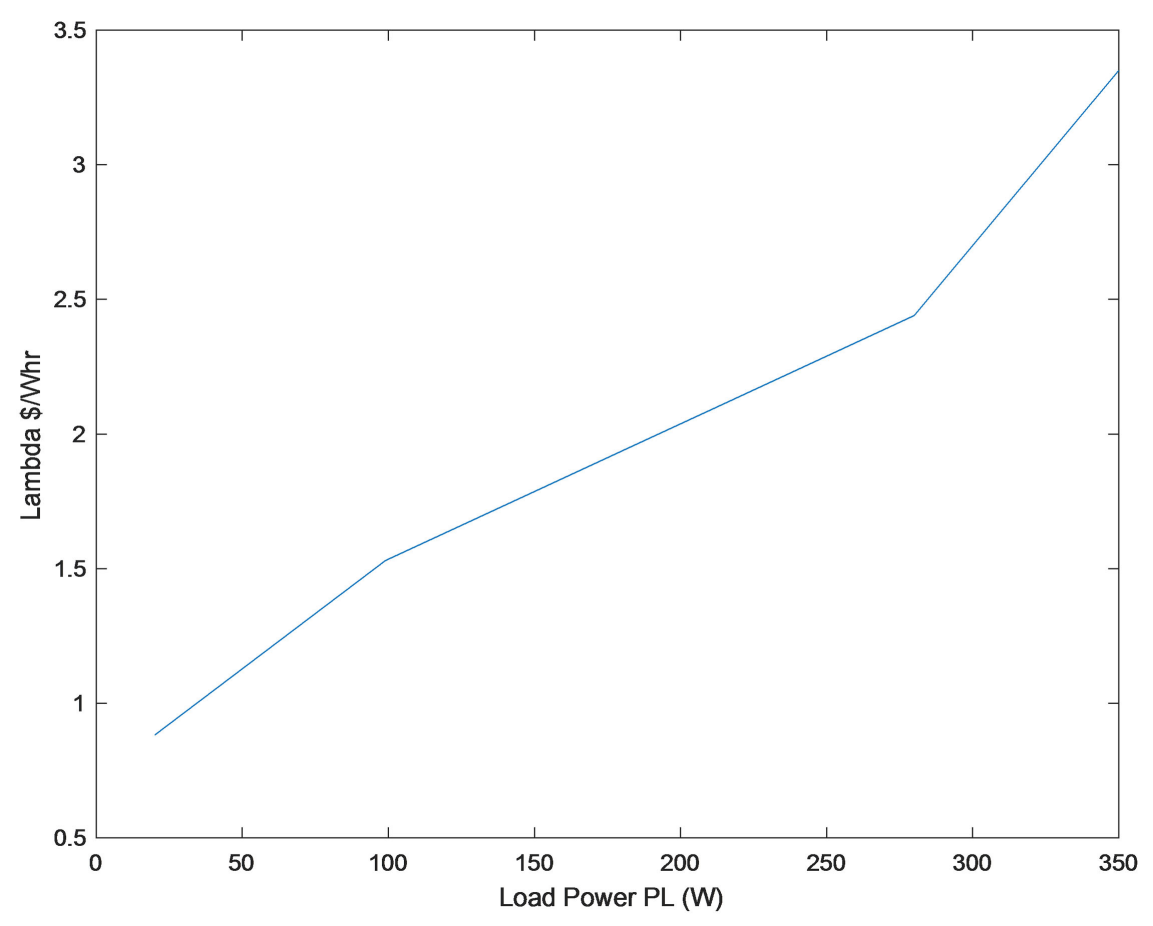

Figure 8. Load Power- $\lambda$ characteristics from MATLAB.

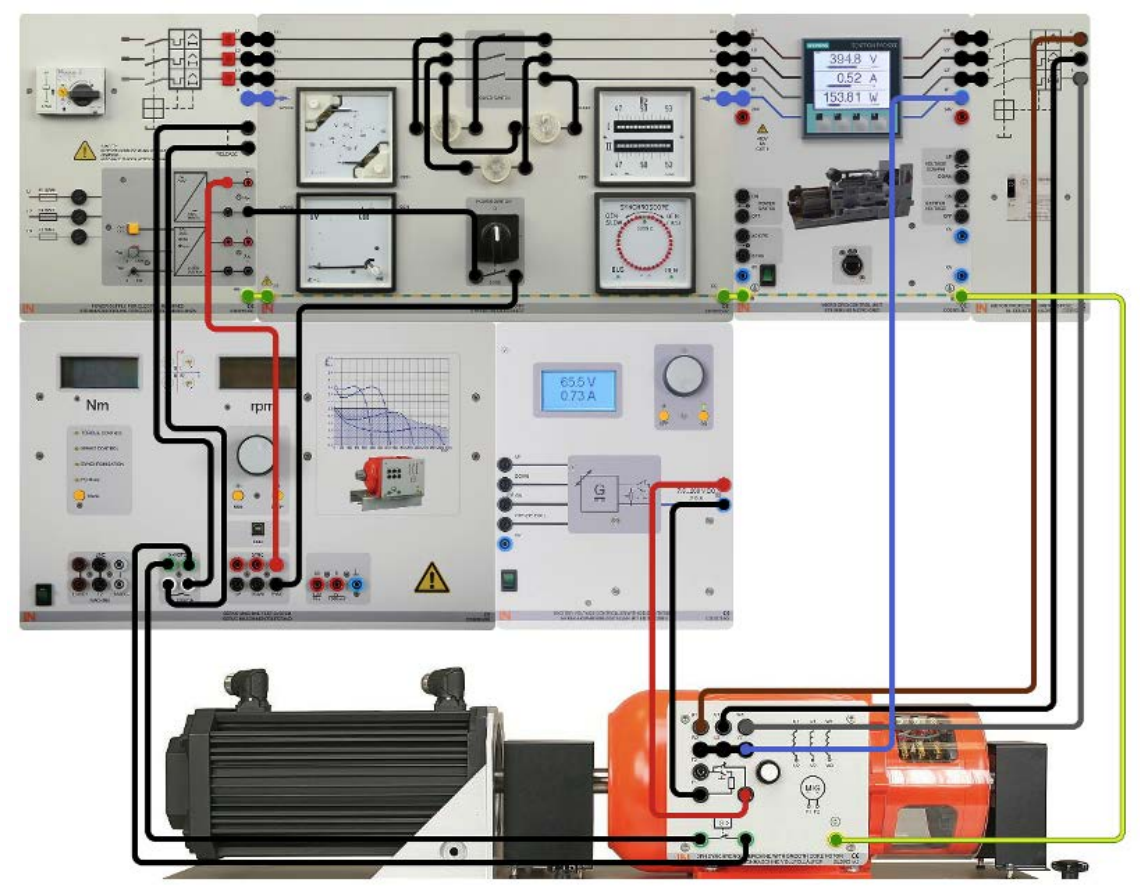

Figure 9. Set-up for manual synchronization using a "dark-lamp synchronization circuit."

A synchronous generator is used as a three-phase synchronous machine. When the speed is around $1800 \mathrm{rpm}$, the exciter voltage is $20 \mathrm{~V}$, and consistent voltage is measured as $212 \mathrm{~V}$. All the incandescent lamps started to get dark. The power switch of the synchronization unit has then connected the generator to 
the grid. Thus, the grid synchronization has been executed with the hydropower plant.

\section{CASE 2: Grid synchronization for a DFIG}

Figure 10 shows the connection of the wind generator to the grid. A doubly-fed asynchronous generator is used to control the variability of wind speed. "WindSim" software is used to emulate the system in real with a servo-machine test.

The generator is synchronizing with the rotor current and is set for a maximum of $0.21 \mathrm{~A}$ and frequency $60 \mathrm{~Hz}$ and variable speed from 210 to $217 \mathrm{~V}$. Then, the generator automatically synchronizes with grid parameters.

\section{CASE 3: The combined connection of hydro and wind generators to the} grid

The synchronization of two renewable power stations together in the SMARTGRID has proposed to observe the optimum power with the SCADA system. This is the following steps of the previous case 1 and case 2. Figure 11 shows that 2 bus-bar systems have been used, where bus 1 is represented as a slack bus. The hydropower plant and wind power plant are connected in parallel to the bus 2. The inductive load is connected through the transmission line.

Usually, the fluctuation rate of output power from the hydro-generator is less than the wind generator's output power. Therefore, DFIGURE is used to generate power in power plants to avoid wind speed variability. Figure 12 indicates the power flow of the system where the regulator helps regulate the generated wind power's viability. Machine-side converters (MSC) and Line-side converters (LSC) are situated to minimize the faults due to wind power fluctuations. The SCADA system was used to control the power flow and reach the optimum generated

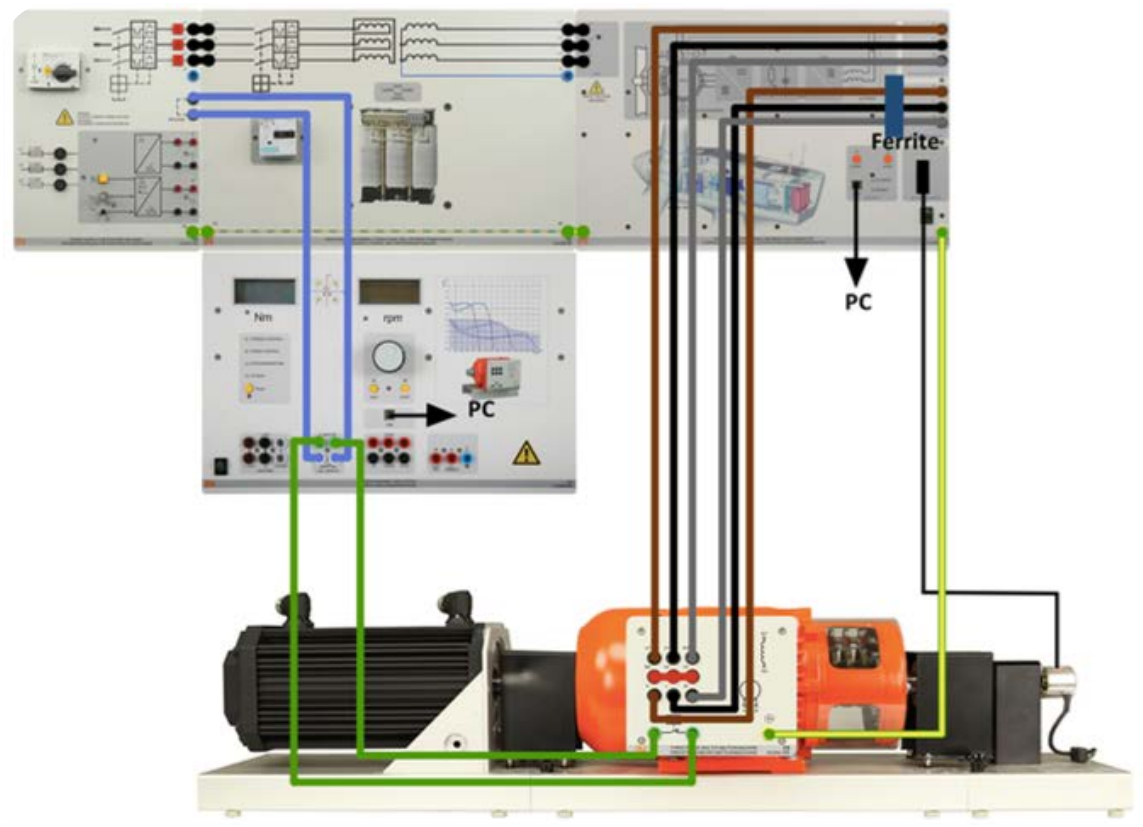

Figure 10. Set-up for manual synchronization using a "dark-lamp synchronization circuit". 


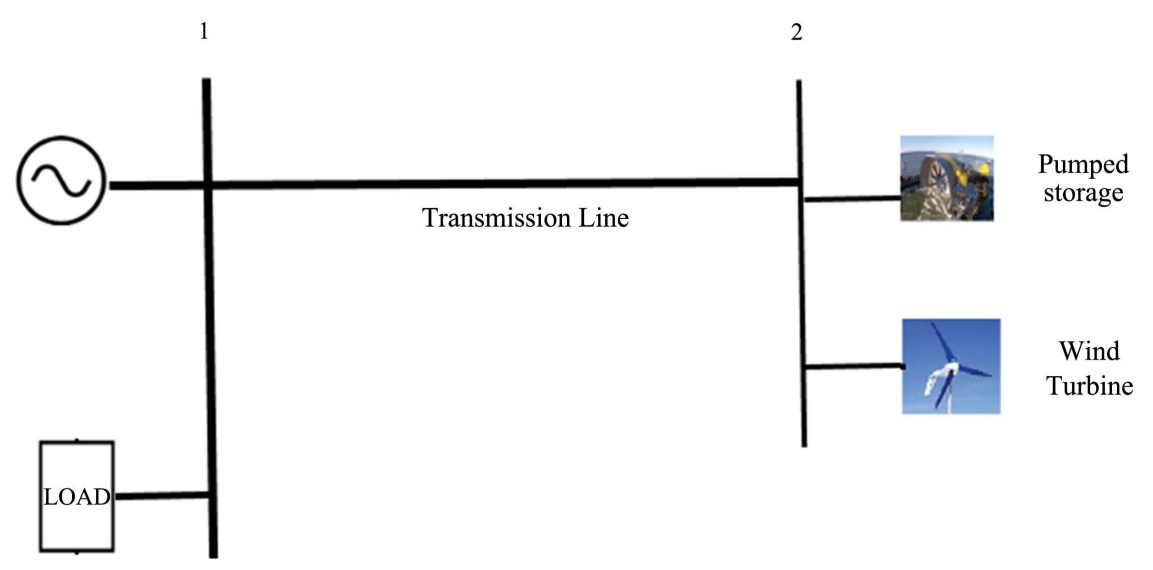

Figure 11. Schematic design of the combined generators.

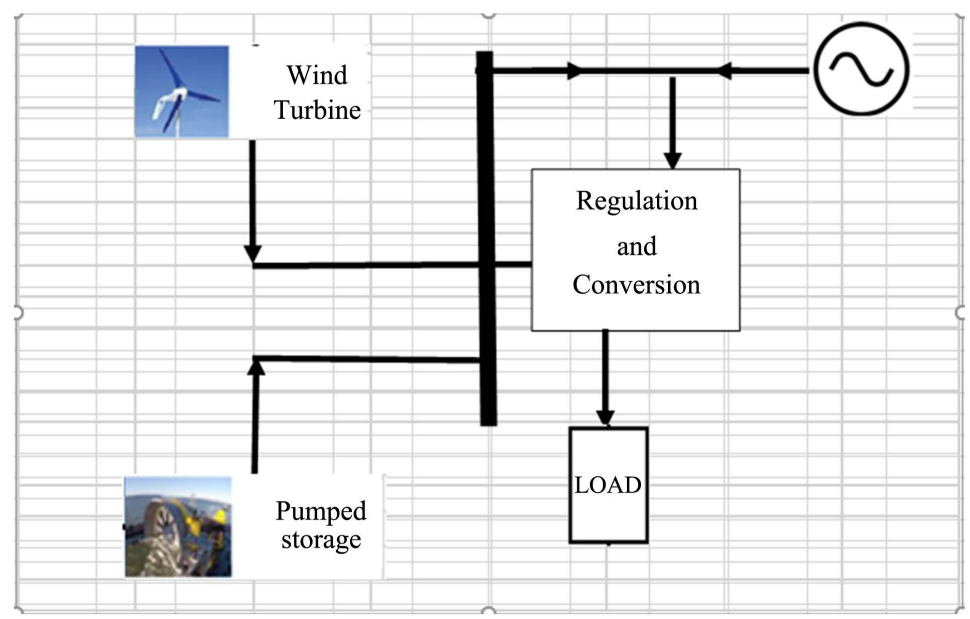

Figure 12. The power flow diagram of the system.

power from both generators individually, synchronized to the grid. Figure 13 has displayed the schematic diagram of the system. Smart grid made SCADA system implemented, and SCADA contributed as an interface with industrial management. Also, this system is integrated by a soft PLC program.

The SCADA designer's main function is to acquire data from the power plants to control the power plant. Sensors, RTU, and HMI, and the communication unit are the four components to interface with the industrial interface, collect and control the entire system's data (Table 3 ).

Total power, $P_{L}=P_{1}+P_{2} ; P_{L}=88+34=122 \mathrm{~W}$.

The combination of pumped storage and wind power plant has provided the optimum power $88 \mathrm{~W}$ and $34 \mathrm{~W}$. The power output of the SCADA designer is matched with the output power from MATLAB.

3) Step Three: (Table 4)

According to the above cost, $\$ 88.76$ was for $870 \mathrm{KWh}$, and the significant cost per KWh is $\$ 0.1020$. In this work, the calculated cost of the output power from both generators is $\$ 59.118$ per Wh is scaled into $\$ 0.0591$ per KWh. In comparison to industry cost charged by actual electricity providers, it can be noted that 


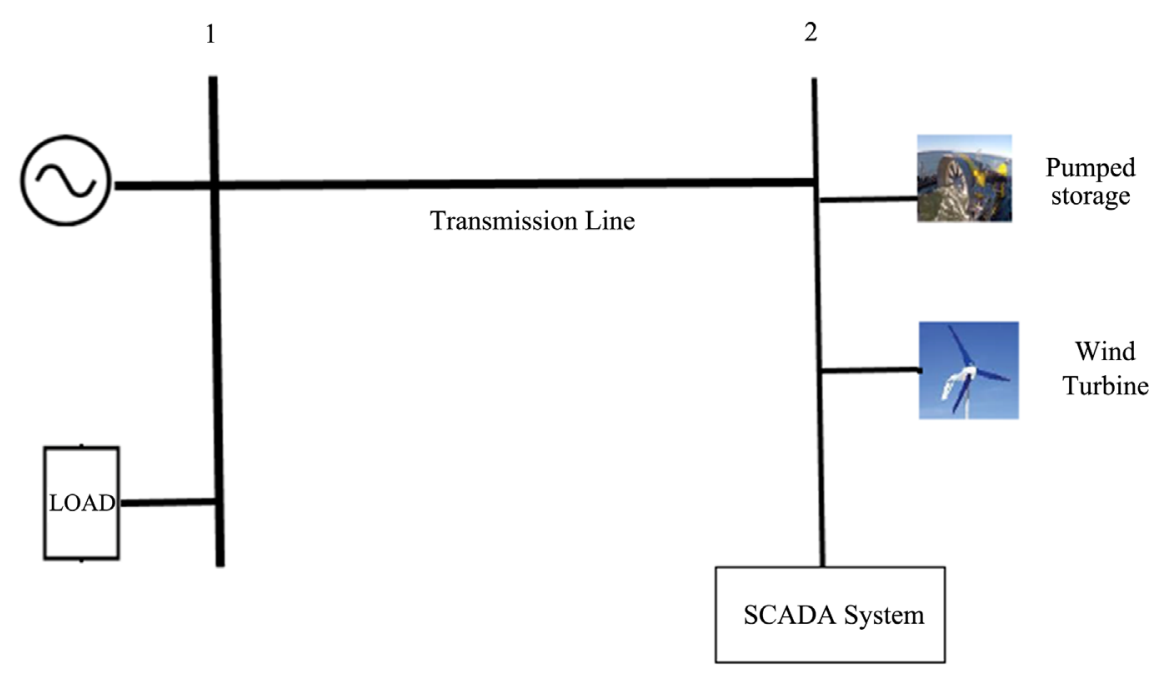

Figure 13. Schematic design with SCADA system.

Table 3. Calculated parameters of pumped storage and wind power plant.

\begin{tabular}{ccc}
\hline Values & Pumped Storage Power Plant & Wind Power Plant \\
\hline Active Power & $88 \mathrm{~W}$ & $34 \mathrm{~W}$ \\
Reactive Power & $238 \mathrm{VAR}$ & $43 \mathrm{VAR}$ \\
Apparent Power & $256 \mathrm{VA}$ & $70 \mathrm{VA}$ \\
\hline
\end{tabular}

Table 4. Cost comparison.

\begin{tabular}{cc}
\hline & Amount in KWh \\
\hline Center point delivery fixed charge & $\$ 40.91$ \\
Energy charge for $870 \mathrm{KWh} @ 0.0550 /$ KWh & $\$ 47.85$ \\
Total cost for 870 KWh & $\$ 88.76$ \\
Effective cost per KWh & $\$ 0.1020$ \\
Optimized cost & $\$ 0.0591$ \\
\hline
\end{tabular}

the optimized cost from this experiment is $\$ 0.0429 / \mathrm{kwh}$ or $42.05 \%$ lesser than the effective cost per kwh charged by Discount Power Energy Corporation (household electricity provider). Considering some other constraints in this work, such as generation limit, transmission losses may vary the system's efficiency.

Significantly, there are few measures taken to optimize the cost by connecting hydroelectric and wind power together with Smart-Grid. At first, the values are taken when pumped storage is connected to the grid. After that, the values are again taken while the grid is associated with the wind power station. The cost was reduced when the combined pumped storage and wind power plant was linked to the grid. In this chapter, the calculations of each power plant are described.

The pumped storage power plant was primarily examined by achieving the manual synchronization to determine the exact point when synchronization oc- 
curs using control lamps and various measuring instruments like a dual-range voltmeter or a synchronoscope. The synchronization requires the same voltage phase angle, same sequence, and the same frequency, and for the parallel of the connection, the RMS voltages should be equal. A dual-range voltmeter is applied to compute the voltage, land the pre-set amplitude of the generated voltage was adjusted by exciting voltage. Also, a dual-range frequency meter is used to display the frequency.

The specification of individual power plants is achieved while the individual generators are connected. When the generators are individually connected, the power generation is low, $28 \mathrm{~W}$, and $13 \mathrm{~W}$ for pumped storage and wind power plants. In contrast, the generated power of the combined system from each generator is $88 \mathrm{~W}$ and $34 \mathrm{~W}$, respectively. The joint hydro-wind system can increase the generation of power. The unstable wind power was stable with the DC chopper, crowbar in the DFIG. With the limit consideration from $10 \mathrm{~W}<P_{1}<$ $200 \mathrm{~W}$ for pumped storage power plant and $10 \mathrm{~W}<P_{2}<150 \mathrm{~W}$ for wind power stand, MATLAB is used to calculate the optimum power generation, which is 88 W for $P_{1}$ and $33.994 \mathrm{~W}$ for $P_{2}$.

\section{Conclusions}

This experiment is focused conducted to optimize the cost of power generation through pumped storage power plant and wind power plant. The entire modeling of cost optimization was conducted in two parts. The mathematical modeling was done using MATLAB simulation while the hydro and wind power plant's emulation was performed using SCADA designer implementation. The experiment was conducted using ranges of generated power from both power sources. The optimum combination of output power and cost from both generators is determined via MATLAB simulation within the assumed generated output power range. The hydro-generator and wind generator's emulation were executed individually through synchronizing the grid to determine each generator's specification using SCADA designer, which provided the optimum power generation from both generators with the specific speed, aligning with results generated through MATLAB. DFIGURE was used to stabilize the unstable output power from the wind power plant. Combining the pumped-storage power plant and wind power plant's generated power increases the system's flexibility and reliability accordingly. Finally, the operational power cost (with no losses consideration) from MATLAB was compared with the local energy provider to determine the cost-efficiency.

Power optimization has also been achieved when the steady hydropower plant and wind power plant are connected to the grid instead of connecting individually by SCADA. The optimal combination of generated power by hydro-wind joint power plant minimizes the operational cost within the assumed output range of management resolving the multi-dimensional issue with SCADA by operating and controlling the power flow of the system. This experiment uni- 
quely highlights the reliability, cost efficiency and advantageous utilization of SCADA's functional efficiency, mainly in developing countries where it is crucial to reduce operational cost while maximizing power output.

Many sectors and specifications can be expanded to improve the cost optimization power system in the future. Connecting three power plants will possibly make a cost-effective plant instead of combining two power plants. Calculating the total cost, including operational cost and installation cost, need to be considered to develop the power system. Power loss may also be explored in the future. Future work can also explore the load curve for annual energy consideration with time. Besides, the capacitor's injecting may improve the power factor that reduces the power system's cost. Furthermore, artificial intelligence methods may be the next step as a genetic algorithm, PSO, to establish a more efficient power system.

\section{Conflicts of Interest}

The authors declare no conflicts of interest regarding the publication of this paper.

\section{References}

[1] Liu, Y. and Shang, T. (2007) Economic Dispatch of Power System Incorporating Windpower Plant. The 8 th International Power Engineering Conference (IPEC 2007), 159-163.

[2] Qiu, W., Zhang, J.H. and Liu, N. (2011) Model and Solution for Environmental/Economic Dispatch Considering Large-Scale Wind Power Penetration. Proceedings of the CSEE, 31, 8-16.

[3] Chen, D.J., Gong, Q.W., Qiao, H., et al. (2012) Multiobjective Generation Dispatching for Wind Power Integrated System Adopting Improved Biogeography-Based Optimization Algorithm. Proceedings of the CSEE, 32, 150-158.

[4] Peng, C.H., Sun, H.J., Guo, J.F., et al. (2012) Dynamic Economic Dispatch for Wind-Thermal Power System Using a Novel Bi-Population Chaotic Differential Evolution Algorithm. International Journal of Electrical Power \& Energy Systems, 42, 119-126. https://doi.org/10.1016/j.ijepes.2012.03.012

[5] Bayon, L., Grau, J.M. and Ruiz, M.M. (2012) The Exact Solution of the Environmental/Economic Dispatch Problem. IEEE Transactions on Power Systems, 27, 723-731. https://doi.org/10.1109/TPWRS.2011.2179952

[6] Yang, L.Q., Lin, S.J., Liu, M.B., et al. (2014) Multiobjective Dynamic Optimal Dispatch for Large-Scale Power Systems Considering Wind Power Penetration. Transactions of China Electrotechnical Society, 29, 286-295.

[7] Narimani, H., et al. (2018) A Multi-Objective Framework for Multi-Area Economic Emission Dispatch. Energy, 154, 126-142.

https://doi.org/10.1016/j.energy.2018.04.080

[8] Azizivahed, A., Naderi, E., Karandeh, R., Cecchi, V., Li, L., Zhang, J.F., et al. (2020) Multi-Area Dynamic Economic Dispatch Considering Water Consumption Minimization, Wind Generation, and Energy Storage System. IEEE Power \& Energy Society Innovative Smart Grid Technologies Conference (ISGT), Washington, 17-20 February 2020, 1-2. https://doi.org/10.1109/ISGT45199.2020.9087689 
[9] Yu, J., Ren, J.W. and Zhou, M. (2013) A Chance-Constrained Programming Based Dynamic Economic Dispatch of Wind Farm and Pumped-Storage Power Station. Journal of Power System Technology, 37, 1-3.

[10] Li, H.L., Zhang, Z.Q. and Tang, X.J. (2015) Research on Optimal Capacity of Large Wind Power Considering Joint Operation with Pumped Hydro Storage. Power System Technology, 2746-2750.

[11] Zhou, Y.F., Wei, H. and Hong, C.Q. (2011) Beqiun Hu andTaocheng. Modelization and Optimization of Multi-Type Power Generators Joint Scheduling Based on Improved PSO. National High Technology Research and Development Program of China, No. 2011AA.

[12] Wang, S.X., Ju, L.W., Shang, J.C., et al. (2013) Optimization Model and Application of Combined Operation of Wind Power, Hydropower and Pumped Storage Power Stations in Energy-Saving Dispatching Environment. Hydropower Energy Science, 31, 46-50.

[13] Xu, F., Chen, L., Jin, H.P., et al. (2013) Modeling and Application Analysis of Combined Operation of Pumped Storage Power Station and Wind Power. Automation of Electric Power System, 37, 149-154.

[14] You, W.-X., Wang, M.-M., et al. (2019) Research on Optimal Operation of Wind Power-Pumped Storage Joint System Based on Improved Bat Algorithm. International Conference on Intelligent Green Building and Smart Grid (IGBSG2019), Hubei, 6-9 September 2019, 538. https://doi.org/10.1109/IGBSG.2019.8886178

[15] Tankasala, G.R. (2012) Artificial Bee Colony Optimisation for Economic Load Dispatch of a Modern Power System. International Journal of Scientific \& Engineering Research, 3, 3-4. 